\title{
Experimental and statistical investigation of the compressive strength anisotropy in structural concrete
}

Hansen, Soren Gustenhoff; Lauridsen, Jorgen Trankjaer; Hoang, Linh Cao

Published in:

Cement and Concrete Research

Link to article, DOI:

10.1016/j.cemconres.2018.02.011

Publication date:

2018

Document Version

Peer reviewed version

Link back to DTU Orbit

Citation (APA):

Hansen, S. G., Lauridsen, J. T., \& Hoang, L. C. (2018). Experimental and statistical investigation of the compressive strength anisotropy in structural concrete. Cement and Concrete Research, 107, 304-316. https://doi.org/10.1016/j.cemconres.2018.02.011

\section{General rights}

Copyright and moral rights for the publications made accessible in the public portal are retained by the authors and/or other copyright owners and it is a condition of accessing publications that users recognise and abide by the legal requirements associated with these rights.

- Users may download and print one copy of any publication from the public portal for the purpose of private study or research.

- You may not further distribute the material or use it for any profit-making activity or commercial gain

- You may freely distribute the URL identifying the publication in the public portal 


\title{
Experimental and statistical investigation of the compressive strength anisotropy in structural concrete
}

\author{
Søren Gustenhoff Hansen ${ }^{a},{ }^{1}$, Jørgen Trankjær Lauridsen ${ }^{a}$, Linh Cao Hoang $^{b}$ \\ ${ }^{a}$ University of Southern Denmark, Odense, Denmark \\ ${ }^{b}$ Technical University of Denmark, Lyngby, Denmark
}

\begin{abstract}
This paper offers a new and closer look into the strength anisotropy of concrete by presenting the so far largest experimental programme (290 tests) and by presenting an advanced statistical analysis of the results. The experimental investigation sheds light on the influence of several important design parameters and conditions on the anisotropy. This includes the influence of reinforcement, $w / c$-ratio, curing time, load history and structural geometry. For this purpose, cores were drilled out at different angles from beam- and slabs specimens for compressive testing. The main findings include: a) the reference cylinder strength (i.e. $w / c$-ratio) does not have a significant influence on the anisotropy when the anisotropy is quantified as an absolute difference between the strength of cores drilled in the two directions; b) the anisotropy in structural members without load history is less than $5 \mathrm{MPa}$; c) the anisotropy amounts to 5-10 MPa for members with load history.
\end{abstract}

\section{Keywords}

Anisotropy, Concrete compressive strength, Drilled cores, Statistical Analysis, Assessment of load carrying capacity, Existing structures

\section{Introduction}

Strength assessment of existing concrete structures is often based on calculation models developed for design of new structures. In this context, the strength parameters adopted in the calculations are usually determined by test of samples taken from the structure. The concrete compressive strength is mostly determined from test of drilled cores, whose compressive strength is subsequently converted to standard cylinder compressive strength. Due to practical reasons, the cores are always drilled perpendicular to the surface of the structure. However, it is known that the core compressive strength is dependent on the drilling direction, [1-6]. Hughes and Ash [1], for example, found as much as 50 percent strength difference between cores drilled parallel and perpendicular to the casting direction. If this directional dependency (i.e. strength anisotropy) is as dramatic as suggested by Hughes and Ash [1], then the current practice - as described above - to estimate the residual capacity of an existing structure may potentially be misleading.

Despite the relevance and the potential impact on current practices for strength assessment of existing structures, the subject of compressive strength anisotropy has received very little attention in the literature, [1-8]. The few previous studies disagree strongly on the magnitude of the anisotropy; absolute as well as relative. Furthermore, it is difficult to draw any general conclusions from the previous studies, mostly due to three shortcomings. These are:

(1) the sample sizes were small,

(2) the conclusions were drawn without a sound statistical analysis of the results,

\footnotetext{
${ }^{1}$ Corresponding author.

E-mail address: sgh@iti.sdu.dk (S.G. Hansen).
} 
(3) the geometry and origins of the test specimens were not directly comparable to the cores drilled from actual structural members.

As examples of the mentioned shortcomings, it can be mentioned that Hughes and Ash [1] drew their conclusion based on a comparison of two samples only while Leshchinsky [3] and Ergün \& Kürklü [5] drew their conclusions based on a comparison of mean-values without regards to the variances. Johnston [2] and Van Mier [7] studied the anisotropy by testing cubes that were sawn from unreinforced concrete prisms and Leshchinsky [3] drilled cores from unreinforced concrete cubes $(200 \times 200 \times 200 \mathrm{~mm})$.

Hence, even though it is known that the concrete compression strength is direction dependent, it is still debatable how significant the strength anisotropy actually is. Furthermore, the impact of a number of important parameters on the anisotropy, e.g. the reference cylinder strength, the presence of reinforcement and the types of structural members, is presently not known or not fully clarified. Finally, the limited literature on this subject does not make clear distinction between strength anisotropy in new structures without load history and in existing structures with load history. Such a distinction is necessary in order to assess whether the anisotropy is mainly a result of the initial casting condition or if it is also affected by e.g. micro damages and cracking from a load history. An answer to the last question is naturally relevant if the compressive strength should be determined for an existing and damaged structure with the aim of estimating the residual load carrying capacity.

This paper offers a fresh and closer look into the strength anisotropy of concrete by presenting a large experimental programme (comprising 290 test results) and by carrying out a thorough and systematic statistical analysis of the experimental results. The primary aim of the investigation is to quantify the strength anisotropy in test specimens of a size that is sufficiently large to resemble real structural members and at the same time avoid the shortcomings identified in the above. Therefore, both beam- and slab specimens are used to investigate the strength anisotropy and how it is affected by a number of design parameters and conditions, which are relevant from a practical point of view. The investigated design parameters and conditions are: a) the reference cylinder strength, b) the presence of reinforcement, c) the curing time, d) the type of structural members (slabs versus beams) and e) the influence of load history. For the statistical analysis of the experimental results, multiple regression models with interactions of explanatory variables are employed. These models enable a detailed analysis of the significance and the magnitude of the anisotropy and the influences of the studied design parameters and conditions.

Following this introduction, Section 2 will describe anisotropy, after which the experimental programme is outlined in Section 3. The statistical approach is set up in Section 4, followed by an outline of results and data analysis in Section 5. Finally, Section 6 provides a summary and discussion, followed by rounding off conclusions in Section 7.

\section{Anisotropy}

The existence of strength anisotropy in concrete (without a previous load history) is often explained by segregation or water migration in the fresh concrete, which causes weak interfaces or initial micro cracks between the cement paste and the undersurface of the large aggregate particles $[1-5,7,8]$. The most commonly used measure for anisotropy is the ratio between the concrete core compressive strength parallel to the casting direction $\left(f_{\mathrm{c}, \mathrm{core} \|}\right)$ and the core compressive strength perpendicular to the casting direction $\left(f_{\mathrm{c} \text {,core } \|}\right)$, see also Figure 1. In this paper, the anisotropy will mainly be discussed on the basis of the difference between the core compressive strength parallel and perpendicular to the casting direction, i.e.:

$$
\Delta f_{\mathrm{c}, \text { core }}=f_{\mathrm{c}, \text { core } \|}-f_{\mathrm{c}, \text { core } \perp}
$$

The reason for measuring the anisotropy as an absolute strength difference rather than a strength ratio is that the statistical analyses to be presented below show, that the concrete strength class (i.e. $f_{c, c y l i n}$ ) has no significant influence on $\Delta f_{\mathrm{c}, \mathrm{core}}$. Thus, it is simpler to use Equation (1). A more detailed discussion is provided in Section 6. 


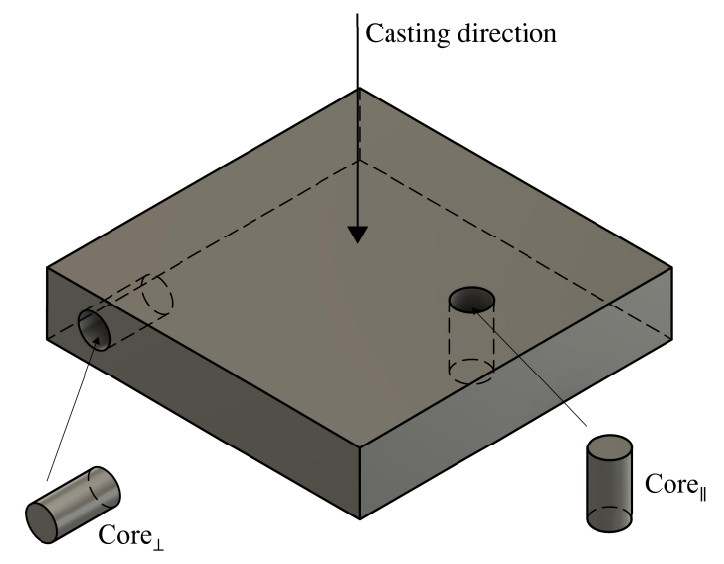

Figure 1: Illustration of a slab with notation of casting and drilling direction.

\section{Experimental programme}

The experimental programme to investigate the anisotropy in structural members with and without load history comprises three test series. Each test series consists of a large number of cores drilled from beam- or slab members produced at a local manufacturer of precast concrete elements. In the following, details of each of the test series are provided. Furthermore, Sub-section 3.4 provides details on the performed compression tests.

\subsection{Test series 1}

The goal of Test series 1 is to investigate the anisotropy in concrete slabs without load history, i.e. to study anisotropy that cannot be attributed to damages or cracking due to previous loading. The parameters varied in this series are the reference cylinder strength, $f_{c, c y l i n}$, (i.e. basically the $w / c$-ratio) and the presence of reinforcement. The influence of the reinforcement is interesting to investigate because the reinforcement mesh in flat slabs (without shear links) may induce unidirectional micro cracks due to anisotropic shrinkage conditions. These micro cracks may influence the strength anisotropy [8].

The drilled cores in this series were obtained from four slabs with the dimensions $1200 \times 1200 \times 200 \mathrm{~mm}$. To study the influence of $f_{c, \text { cylin }}$, two slabs were cast with a relatively low $f_{c, c y l i n}$ (Mix A) and two slabs were conducted with a relatively high $f_{\mathrm{c}, \text { cylin }}$ (Mix B). Details on Mix A and Mix B can be seen in Table 1. To study the influence of the presence of reinforcement for both Mix A and Mix B, one slab contained top and bottom mesh reinforcement and one slab contained no reinforcement. The reinforcement meshes consisted of $\varnothing 6 \mathrm{~mm}$ rebars per $150 \mathrm{~mm}$ in both directions.

Each pair of slabs (Mix A and Mix B) was cast from the same batch of concrete. After casting, the slabs cured for 24 hours covered in plastic before they were demoulded, wrapped in plastic and stored indoor until core drilling.

Cores with a diameter of $100 \mathrm{~mm}$ were drilled with a water-cooled diamond drill according to the drilling plan displayed in Figure 2. The drilling plan ensures that all cores were taken from positions not intersected by rebars. 116 drilled cores were used for compressive tests and 110 were used for split tests (the split tests are not a part of this investigation, see [9]). The cores, used for compressive tests, were grinded in both ends to ensure plane loading surfaces. The height of the cores after grinding is shown in Appendix A. The cores were tested after 83 (Mix A) and 91 (Mix B) days, respectively.

Simultaneously with the production of the slabs, $\varnothing 100 \times 200 \mathrm{~mm}$ cylinders were cast from the same concrete batch in order to determine the reference cylinder strength of each concrete mix. The cylinders were cured under the same conditions as the slabs. Table 2 summarises the number of tested cylinders and cores in Test series 1 . 


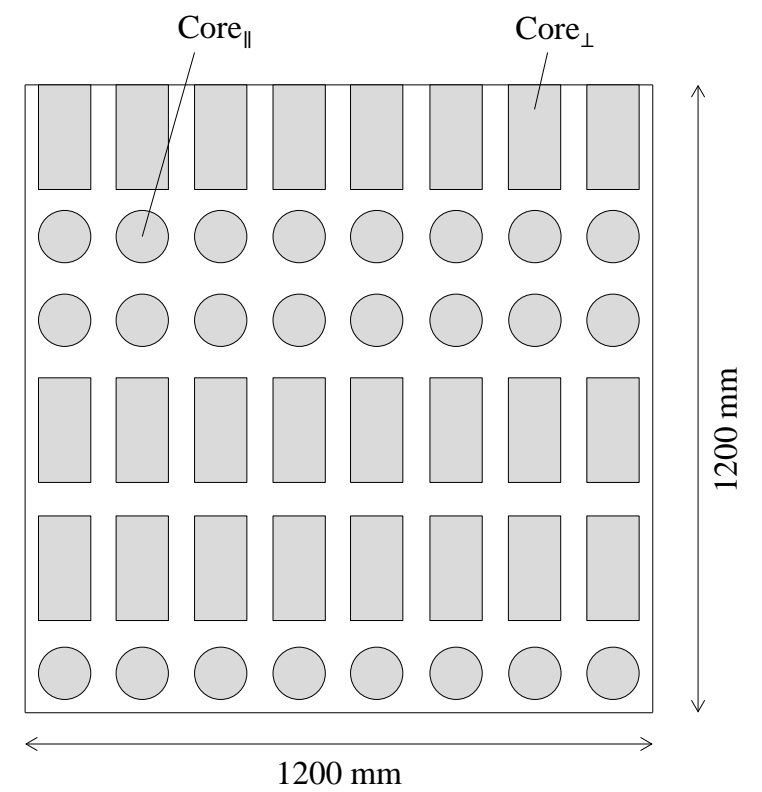

Figure 2: Drilling plan for Test series 1.

Table 1: Concrete mix composition for the three test series.

\begin{tabular}{cllcccc}
\hline Test series & $\begin{array}{l}\text { Max aggregate } \\
\text { size }[\mathrm{mm}]\end{array}$ & $\begin{array}{l}\text { Aggregate } \\
\text { type }\end{array}$ & Cement & $w / c$ & $\begin{array}{l}\text { Air-entraining } \\
\text { admixture }\end{array}$ & $\begin{array}{l}\text { Super- } \\
\text { plasticizer }\end{array}$ \\
\hline 1 - Mix A & 8 & Round & Basis Portland (CEM 52,5) & 0.60 & Yes & Yes \\
1 - Mix B & 8 & Round & Basis Portland (CEM 52,5) & 0.43 & Yes & Yes \\
2 & 16 & Crushed & Rapid Portland (CEM 52,5) & 0.40 & Yes & Yes \\
3 & 8 & Round & Basis Portland (CEM 52,5) & 0.46 & Yes & Yes \\
\hline
\end{tabular}

Table 2: Number of tested cylinders and cores for Test series 1 .

\begin{tabular}{lllll}
\hline & Mix A & & Mix B & \\
& Reinforced slab & Unreinforced slab & Reinforced slab & Unreinforced slab \\
\hline Numbers of core $_{\perp}$ & 15 & 13 & 13 & 12 \\
Numbers of core & 12 & 19 & 14 & 18 \\
Numbers of cylinders & 6 & & 6 & \\
\hline
\end{tabular}




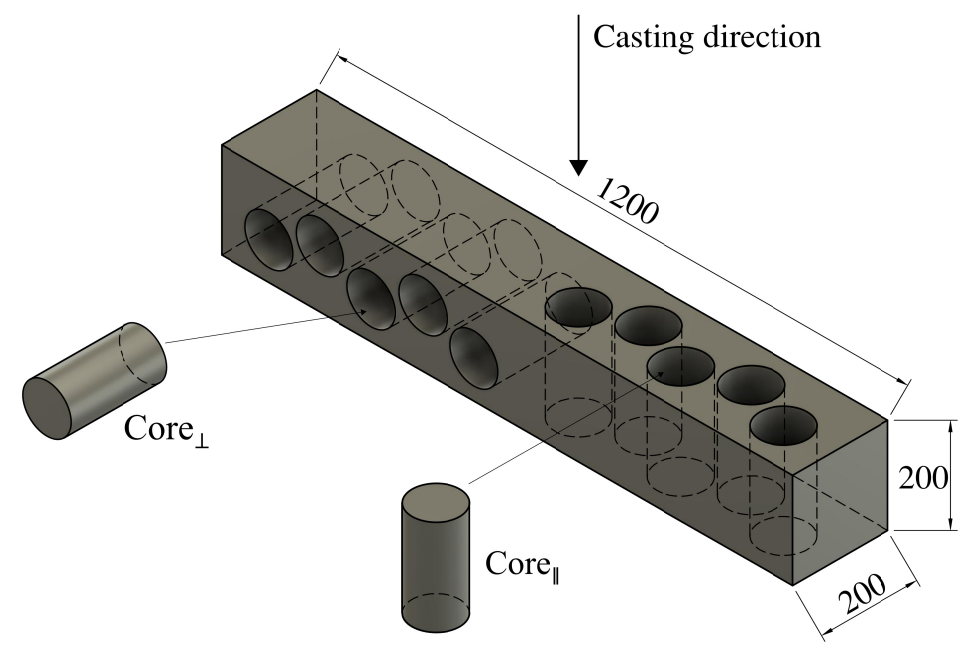

Figure 3: Drilling plan for Test series 2.

Table 3: Number of tested cores and cylinders for Test series 2 .

\begin{tabular}{lllll}
\hline Beam name & 1 & 2 & 3 & 4 \\
\hline Curing time [weeks] & 2 & 4 & 8 & 12 \\
Numbers of core $\perp$ & 3 & 4 & 5 & 5 \\
Numbers of core $_{\text {Numbers of cylinders }}$ & 4 & 5 & 4 & 5 \\
\hline
\end{tabular}

\subsection{Test series 2}

The goal of Test series 2 is to investigate the influence of curing time on the strength anisotropy. For this purpose, cores drilled from beams without load history were tested.

The primary motivation to focus on the curing time in this test series is that the large variation in the strength anisotropy published in the literature is also based on test specimens with very different curing times. Hence, it is relevant to investigate the correlation and possibly provide a partial explanation for the published results.

The drilled cores were obtained from four unreinforced beams with dimensions $204 \times 204 \times 1200 \mathrm{~mm}$. Details on the concrete mix composition may be found in Table 1 . The beams were cast from the same batch of concrete and cured for 18 hours covered in plastic before they were demoulded. The beams were subsequently wrapped in plastic and stored indoor for further curing until it was time for core drilling.

Drilling of the $\varnothing 99 \mathrm{~mm}$ cores took place according to the plane displayed in Figure 3 . The curing time until core drilling and testing was different for the four beams (2, 4, 8 and 12 weeks respectively). When necessary, the cores were grinded before testing to ensure a plane loading surface. The height of the cores after grinding was $200 \pm 1 \mathrm{~mm}$.

Simultaneously with the production of the beams, a number of cylinders $(\varnothing 100 \times 200 \mathrm{~mm})$ was cast in order to determine the reference cylinder strength for the four curing times $(2,4,8$ and 12 weeks). The cylinders were produced and cured under the same conditions as the beams. The number of tested cylinders and cores in Test series 2 is provided in Table 3.

\subsection{Test series 3}

The goal of Test series 3 is to investigate the anisotropy in structural members with load history. For this purpose, cores were drilled from 12 reinforced beams that had been used for shear testing in another research project [10]. The dimensions of the beams were $172 \times 400-500 \times 5000 \mathrm{~mm}$. The beams contained top and 
bottom longitudinal reinforcement and were in addition provided with stirrups at both ends. Details of the reinforcement layout for each of the beams are provided in Appendix B. The beams were cast from individual concrete batches, but based on the same concrete mix recipe. Details on the concrete mix composition can be seen in Table 1.

Shear tests were carried out approximately 45 days after casting. Figure 4 illustrates the shear test setup with the beam specimen divided into three shear loaded zones. The point loads, $P$, were applied in a deformation controlled manner until shear failure in one of the shear zones occurred. The failed shear zone was thereafter externally strengthened (with threaded bars and steel plates) and the test was thereafter repeated until failure had occurred in all three shear zones. Figure 4 also indicates the extent of shear cracking and the actual shear failures in the beam.

After of the shear tests, some beams were stored indoor whilst some beams were stored outdoor. No frost occurred during the outdoor storage. 360-370 days after casting, cores with a diameter of $95 \mathrm{~mm}$ were drilled from the beams. The cores were taken from areas without visual cracks from the shear tests, (see indication in Figure 4). It should be noted that for the beams in this test series, cores parallel to the casting direction $\left(\right.$ core $\left._{\|}\right)$corresponds to those drilled horizontally while cores perpendicular to the casting direction (core $\perp$ ) were drilled from the top of the beam. When necessary, the cores were grinded before testing to ensure a plane loading surface. The height of the cores after grinding is provided in Appendix A. An overview of the number of tested cores per beam is provided in Table 4.

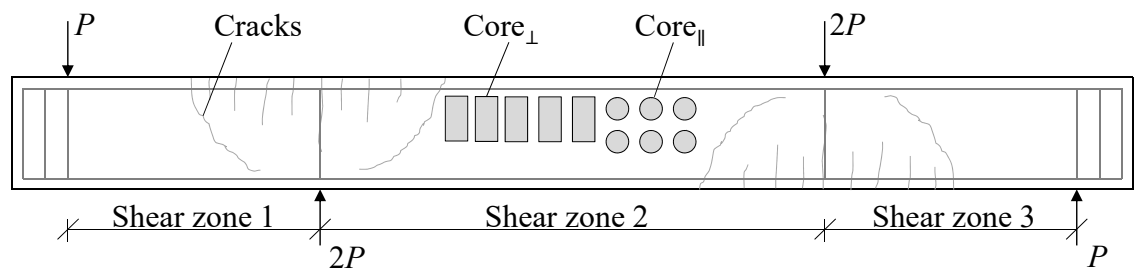

Figure 4: Illustration of the beam shear test setup with indication of shear cracks and positions of core drilling for Test series 3.

Table 4: The number of tested cores per beam for Test series 3 .

\begin{tabular}{lcccccccccccc}
\hline Beam name & 11 & 12 & $2 \mathrm{a} 1$ & $2 \mathrm{c} 2$ & $3 \mathrm{a} 1$ & $3 \mathrm{a} 2$ & $3 \mathrm{~b} 1$ & $3 \mathrm{~b} 2$ & $5 \mathrm{a} 1$ & $5 \mathrm{a} 2$ & $6 \mathrm{~b} 1$ & $6 \mathrm{~b} 2$ \\
\hline Core $_{\perp}$ & 6 & 6 & 2 & 6 & 6 & 6 & 6 & 6 & 6 & 5 & 6 & 6 \\
Core $_{\Perp}$ & 6 & 7 & 6 & 6 & 6 & 6 & 5 & 6 & 6 & 6 & 6 & 6 \\
\hline
\end{tabular}

\subsection{Tests}

All compression tests were carried out in an electro-mechanical compression machine with a capacity of 1200 $\mathrm{kN}$. The load was applied in a displacement controlled manner with a constant velocity of $1.0 \mathrm{~mm} / \mathrm{min}$ in Test series 1 and 3 and $0.42 \mathrm{~mm} / \mathrm{min}$ in Test series 2 . The tests were conducted without interlayers between the steel loading plates and the specimens. The upper loading plate was free to rotate during the entire test, while the lower load plate was in a fixed position.

\section{Multiple linear regression with interaction}

For the statistical analysis, multiple linear regression models are employed on the data [11,12]. A brief introduction to the theoretical background will be provided in this section. Sub-section 4.1 provides a general introduction to regression models. Sub-section 4.2 describes the general form of the regression model adopted in this research. Sub-section 4.3 explains how the anisotropy is quantified by the use of regression models. Sub-section 4.4 and 4.5 provide details on the statistical interference and diagnostics respectively. 


\subsection{Regression models}

Regression models are used to predict the value of a certain response variable (here, core compressive strength) based on the values of certain explanatory variables (here, the drilling direction and the design parameters). Linear regression models assume that the influences, or 'effects', of these explanatory variables can be added according to a linear model. Regression models may account for both 'main effects' and 'interaction effects'. The main effects regard the direct influence of the explanatory variables on the response variable (e.g. the direct increase of the core compressive strength with the reference cylinder strength), while the interaction effects account for the case where the effect of a variable is depending on the level of the other variable.

\subsection{General form}

The general form of the regression model adopted in this research is provided in Equation (2). The model predicts the core compressive strength $\left(f_{\mathrm{c}, \text { core }}\right)$ on the basis of the drilling direction $\left(x_{\mathrm{dir}}\right)$ and the design parameters of interest $\left(x_{1}, \ldots x_{\mathrm{n}}\right)$. The regression model accounts for all main effects. As the main interest goes to the dependency of the core compressive strength as a function of drilling direction, the model additionally accounts for the interaction effects between the drilling direction $\left(x_{\text {dir }}\right)$ and the design parameters of interest $\left(x_{1}, \ldots x_{\mathrm{n}}\right)$. The general form of the regression model can be described by:

$$
f_{\mathrm{c}, \text { core }}=\beta_{0}+\beta_{\mathrm{dir}} x_{\mathrm{dir}}+\sum_{i=1}^{\mathrm{n}} \beta_{i} x_{i}+\theta_{i} x_{i} x_{\mathrm{dir}} \pm \varepsilon
$$

The parameters $\beta_{0}$ to $\beta_{\mathrm{n}}$ are the regression coefficients for the main effects and the parameters $\theta_{1}$ to $\theta_{\mathrm{n}}$ are the regression coefficients for the interaction effects. The term $\varepsilon$ represents the random error.

Depending on the performed statistical analysis, the regression model may consist of both quantitative and qualitative explanatory variables. In this research, the drilling direction $\left(x_{\mathrm{dir}}\right)$, the presence of reinforcement $\left(x_{\rho}\right)$ and the reference cylinder strength, represented by the type of concrete mix, $\left(x_{\text {mix }}\right)$ are taken as qualitative explanatory variables, where the curing time $\left(x_{\text {time }}\right)$ is taken as a quantitative explanatory variable. The program used for analysis (JMP) uses effect coding to include qualitative explanatory variables, where it typifies binary qualitative variables with states -1 and 1 . For example, the explanatory variable $x_{\text {dir }}$ takes the following values:

$$
x_{\mathrm{dir}}= \begin{cases}-1 & \text { in case of core }{ }_{\perp} \\ 1 & \text { in case of core } \|\end{cases}
$$

The effect coding is used rather than dummy (0-1) coding, because the coefficient provides the difference from overall mean for the two cores, rather than the difference between them.

\subsection{Quantification of anisotropy}

To quantify the anisotropy, $f_{\mathrm{c}, \text { core }}$ needs to be predicted for both drilling directions, i.e. $f_{\mathrm{c}, \text { core } \perp}$ and $f_{\mathrm{c}, \mathrm{core} \|}$. By substituting Equation (3) in the regression model, this results in:

$$
\begin{aligned}
& f_{\mathrm{c}, \mathrm{core} \perp}=\beta_{0}-\beta_{\mathrm{dir}}+\sum_{i=1}^{\mathrm{n}} \beta_{i} x_{i}-\theta_{i} x_{i} \pm \varepsilon \\
& f_{\mathrm{c}, \text { core } \|}=\beta_{0}+\beta_{\mathrm{dir}}+\sum_{i=1}^{\mathrm{n}} \beta_{i} x_{i}+\theta_{i} x_{i} \pm \varepsilon
\end{aligned}
$$

When implemented in Equation (1), this results in the following prediction formula for the anisotropy:

$$
\Delta f_{\mathrm{c}, \mathrm{core}}=2 \beta_{\mathrm{dir}}+2 \sum_{i=1}^{\mathrm{n}} \theta_{i} x_{i}
$$


This means that the anisotropy $\Delta f_{\mathrm{c}, \mathrm{core}}$ can be predicted as a function of the obtained regression coefficients $\beta_{\mathrm{dir}}$ and $\left\{\theta_{i}\right\}$ combined with the values for the design parameters $\left\{x_{i}\right\}$. This means that the regression coefficients $\left\{\theta_{i}\right\}$ provide an estimate of the influence of their corresponding design parameters $\left\{x_{i}\right\}$ on the anisotropy. The total influence of the design parameters on the anisotropy is estimated by:

$$
\Delta f_{\mathrm{c}, \operatorname{core} \theta}=2 \sum_{i=1}^{\mathrm{n}} \theta_{i} x_{i}
$$

\subsection{Statistical inference}

In Test series 1 and 2 two regression analyses are conducted. In the first analysis, the influence of the design parameters on the anisotropy is investigated. For this, the full regression model as provided in Equation (2) is evaluated. The influence of the design parameters is assessed through the $(i)$ significance and $(i i)$ the magnitude of the regression coefficients of the interaction effects $\left\{\theta_{i}\right\}$. In the second analysis, the anisotropy is investigated. This is done on the basis of an updated regression model, where the insignificant effects of the design parameters found from the first analysis are excluded. The anisotropy is assessed on its $(i)$ significance and $(i i)$ its magnitude.

\subsection{Diagnostics}

For each regression analysis, diagnostics are performed and only regression models where all regression assumptions were valid are used, including assessment of normal distribution of the residual, which is a condition for valid statistical conclusions. The diagnostics and the result of these are not shown in this paper but can be found in the background report to this research project, see [13].

\section{$5 \quad$ Results and data analysis}

The experimental results will be presented as box plots. The results are also tabulated in Appendix A.

\subsection{Test series 1}

Figure 5 shows a box plot of the test results from Test series 1 . The following can be observed:

- The median of $f_{\mathrm{c}, \text { core }}$ is higher for Mix B than for Mix A. This is expected, as $f_{\mathrm{c}, \mathrm{cylin}}$ of Mix B is higher than for Mix A.

- The median of $f_{c, \text { core }}$ seems to be slightly higher for the slabs with reinforcement than for the slabs without reinforcement.

- $f_{\mathrm{c}, \mathrm{core} \perp}$ seems systematically lower than $f_{\mathrm{c}, \mathrm{core} \|}$.

\subsubsection{Influence of the design parameters on the anisotropy}

The following regression model is adopted for the first data analysis:

$$
f_{\mathrm{c}, \text { core }}=\beta_{0}+\beta_{\mathrm{dir}} x_{\mathrm{dir}}+\beta_{\text {mix }} x_{\text {mix }}+\beta_{\rho} x_{\rho}+\theta_{\text {mix }} x_{\text {mix }} x_{\text {dir }}+\theta_{\rho} x_{\rho} x_{\mathrm{dir}} \pm \varepsilon
$$

Interest goes to the regression coefficients $\theta_{\text {mix }}$ and $\theta_{\rho}$, which provide an estimate on the influence of the reference cylinder strength $\left(f_{\mathrm{c}, \mathrm{cylin}}\right)$, represented by the type of concrete mix, and the presence of reinforcement on the anisotropy respectively. Their estimates and corresponding $p$-values are provided in Table 5 .

The influence of $f_{\mathrm{c}, \mathrm{cylin}}$ and the presence of reinforcement is assessed through the $(i)$ significance and $(i i)$ the magnitude of the regression coefficients $\theta_{\text {mix }}$ and $\theta_{\rho}$; 
Figure 5: Box plot of the test results $\left(f_{c, c o r e}\right)$ for Test series 1.

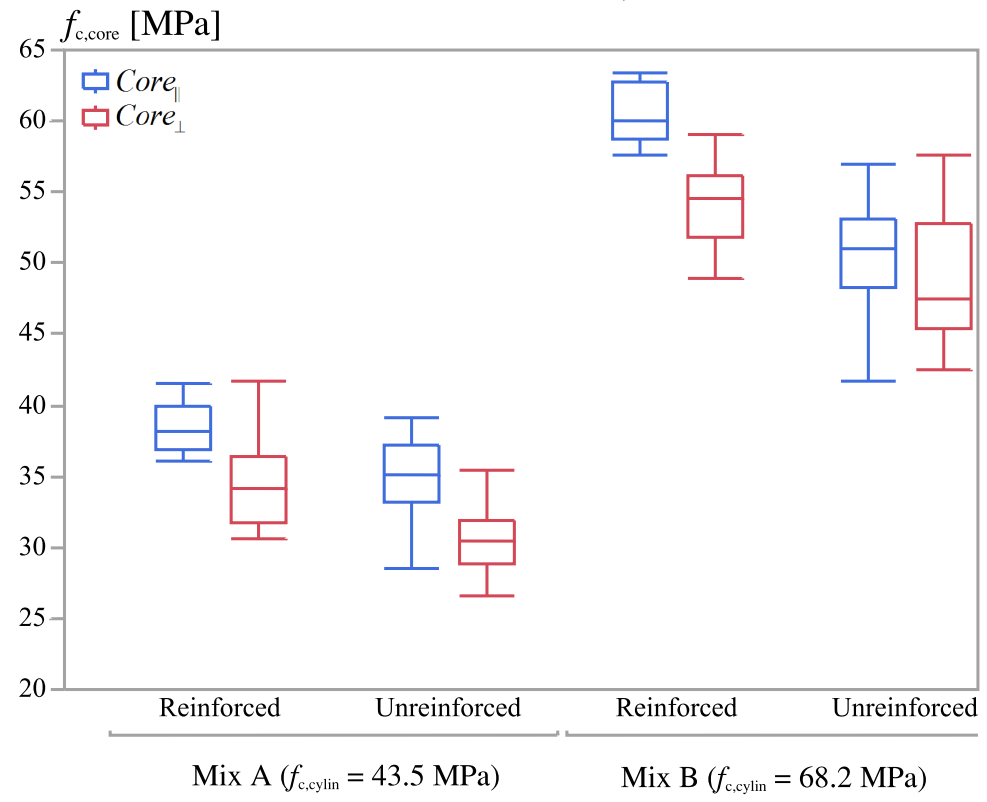

Table 5: Estimates of the regression coefficients.

\begin{tabular}{lll}
\hline & Estimate & $p$-value \\
\hline$\theta_{\text {mix }}$ & $0.29 \mathrm{MPa}$ & 0.38 \\
$\theta_{\rho}$ & $0.61 \mathrm{MPa}$ & 0.065 \\
\hline
\end{tabular}

\section{i Significance}

Both regression coefficients have a $p$-value above 5 percent. This means that there is not sufficient evidence to state that $f_{c, c y l i n}$ or the presence of reinforcement have a significant influence on the anisotropy.

ii Magnitude

The total influence of the design parameters on the anisotropy is quantified by (see Equation (6)):

$$
\Delta f_{\mathrm{c}, \text { core }, \theta}=2\left(\theta_{\text {mix }} x_{\text {mix }}+\theta_{\rho} x_{\rho}\right)
$$

where $x_{\text {mix }}$ takes the value 1 in the case of Mix A and the value -1 in the case of Mix B and $x_{\rho}$ takes the value 1 in case of reinforced concrete and the value -1 in the case of unreinforced concrete. A visualisation of the equation is displayed in Figure 6. The anisotropy is slightly larger for Mix A than for Mix B (difference of 1.2 MPa). The anisotropy is slightly larger in the case of reinforced concrete than for unreinforced concrete (difference of $2.4 \mathrm{MPa}$ ).

Based on the evaluation of the significance as well as the magnitude, it can be concluded that the influence of $f_{c, c y l i n}$ and the presence of reinforcement on the anisotropy is small.

The regression analysis identifies 4 possible outliers. A regression analysis where the possible outliers are excluded shows the same as the shown analysis. The $p$-value for $\theta_{\text {mix }}$ and $\theta_{\rho}$ is found even higher. The outliers are excluded in the further analysis.

\subsubsection{Significance and magnitude of the anisotropy}

Since the first regression analysis shows that the influence of the $f_{\mathrm{c}, \text { cylin }}$ and the presence of reinforcement on the anisotropy is insignificant, the anisotropy is further studied by a regression model without the interaction effects. The following regression model is adopted: 
Figure 6: Estimated influence of the reference cylinder strength and the presence of reinforcement on the anisotropy.

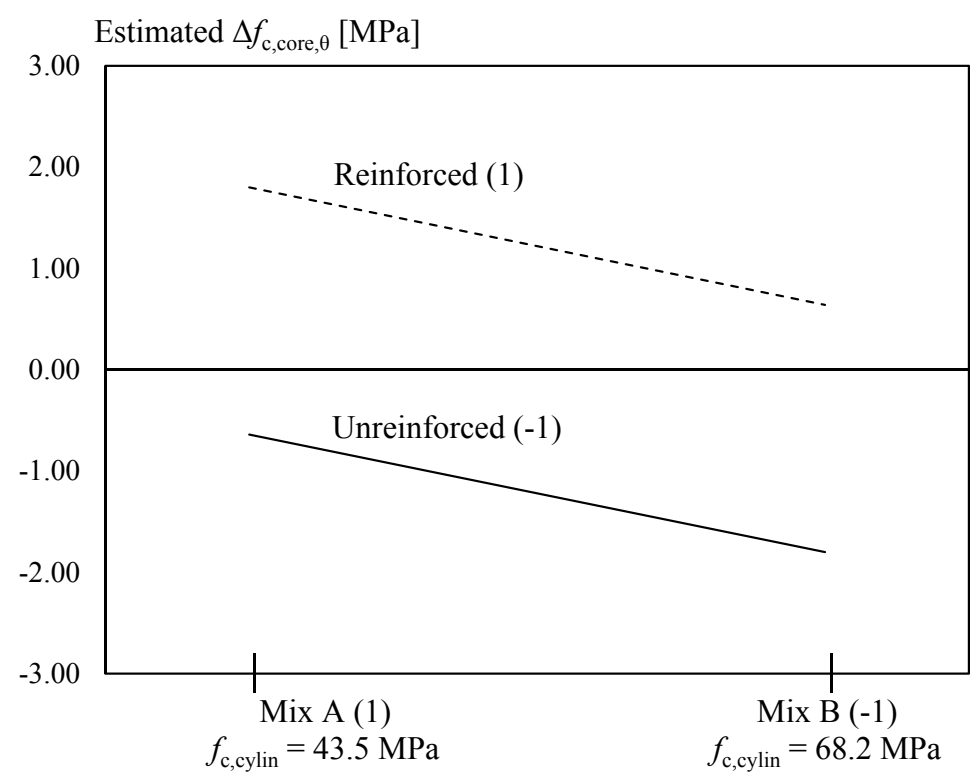

Table 6: Estimate of the regression coefficient

\begin{tabular}{lll}
\hline & Estimate & $p$-value \\
$\beta_{\text {dir }}$ & $2.27 \mathrm{MPa}$ & $<0.0001$ \\
\hline
\end{tabular}

$$
f_{\mathrm{c}, \mathrm{core}}=\beta_{0}+\beta_{\mathrm{dir}} x_{\mathrm{dir}}+\beta_{\text {mix }} x_{\text {mix }}+\beta_{\rho} x_{\rho} \pm \varepsilon
$$

Interest goes to the regression coefficient $\beta_{\mathrm{dir}}$, which provide an estimate on the anisotropy. The estimate and corresponding $p$-value of the regression coefficient are provided in Table 6.

The anisotropy is assessed through the $(i)$ significance and $(i i)$ the magnitude of the regression coefficient $\beta_{\text {dir }}$

i Significance

The regression coefficient shows an extremely low $p$-value. This means that there is an extremely strong evidence that the concrete core compressive strength is anisotropic.

ii Magnitude

The anisotropy is quantified by Equation (5) without the interaction effects:

$$
\Delta f_{\mathrm{c}, \text { core }}=2 \beta_{\text {dir }}
$$

The mean of the anisotropy of the concrete core compressive strength is $4.5 \mathrm{MPa}$ and the corresponding 95 percent confidence interval is [3.4 to $5.7 \mathrm{MPa}]$.

If the outliers are included in the analysis the mean anisotropy is found to $4.3 \mathrm{MPa}$.

\subsection{Test series 2}

Figure 7 shows a box plot of the test results from Test series 2. The following can be observed:

- $f_{\mathrm{c}, \text { core }}$ increases with increasing curing time, as expected. 


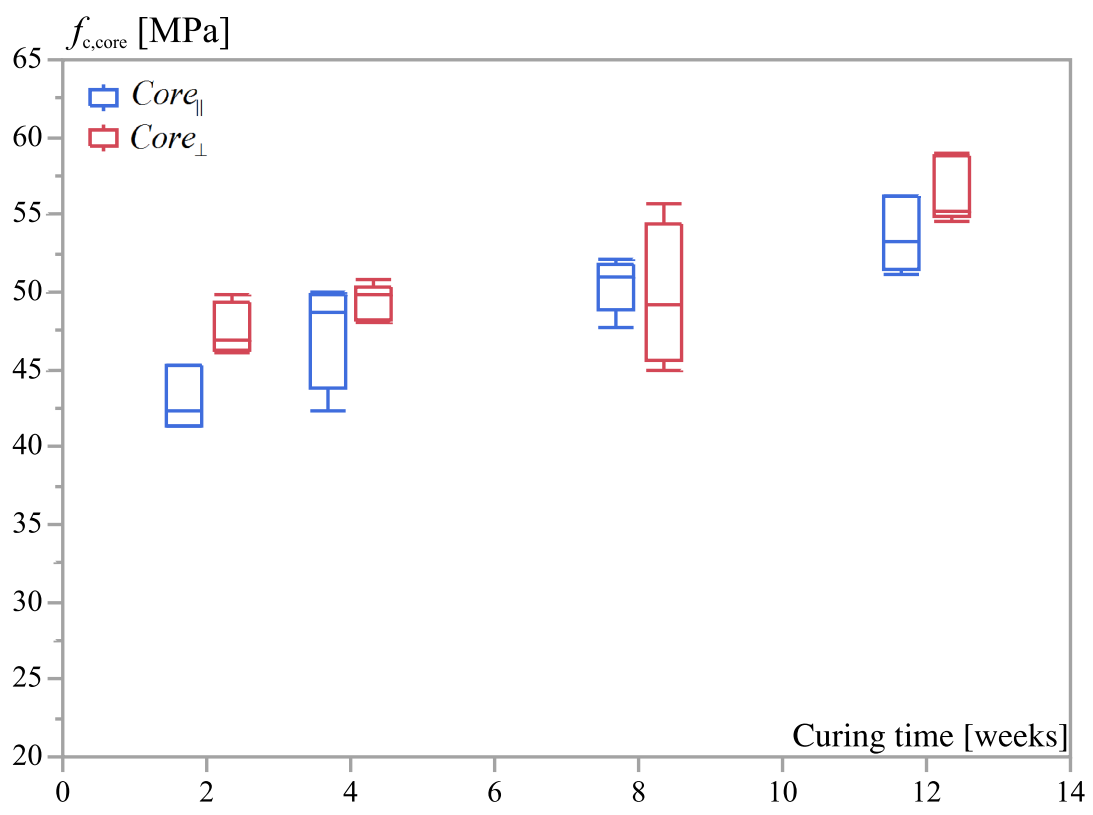

Figure 7: Box plot of the test results $\left(f_{\mathrm{c}, \mathrm{core}}\right)$ for Test series 2 .

Table 7: Estimate of the regression coefficient.

\begin{tabular}{lll}
\hline & Estimate & $p$-value \\
$\theta_{\text {time }}$ & $0.07 \mathrm{MPa} /$ week & 0.5786 \\
\hline
\end{tabular}

- For 2 weeks, 4 weeks as well as 12 weeks curing, $f_{\mathrm{c}, \mathrm{core} \perp}$ is slightly higher than $f_{\mathrm{c}, \mathrm{core} \|}$. This is opposite to the results from Test series 1 , where $f_{\mathrm{c}, \mathrm{core} \perp}$ was systematically lower than $f_{\mathrm{c}, \text { core } \|}$. A detailed discussion on this is provided in Section 6.

\subsubsection{Influence of the design parameters on the anisotropy}

The regression model employed for the first data analysis is shown in Equation (11).

$$
f_{\mathrm{c}, \mathrm{core}}=\beta_{0}+\beta_{\text {dir }} x_{\text {dir }}+\beta_{\text {time }} x_{\text {time }}+\theta_{\text {time }} x_{\text {time }} x_{\text {dir }} \pm \varepsilon
$$

Interest goes to the regression coefficient $\theta_{\text {time }}$, which provides an estimate on the influence of the curing time on the anisotropy. The estimate and corresponding $p$-value of the regression coefficient are given in Table 7.

The influence of the curing time is assessed through the $(i)$ significance and (ii) the magnitude of the regression coefficient $\theta_{\text {time }}$;

i Significance

The regression coefficient has a $p$-value above 5 percent. This means that there is not sufficient evidence to state that the curing time has a significant influence on the anisotropy.

ii Magnitude

The total influence of the curing time on the anisotropy is quantified by:

$$
\Delta f_{\text {c, core }, \theta}=2 \theta_{\text {time }} x_{\text {time }}
$$

where $x_{\text {time }}$ is the curing time in weeks. A visualisation of Equation (12) is displayed in Figure 8. The anisotropy is slightly larger after 12 weeks than after 2 weeks (difference of $1.3 \mathrm{MPa}$ ). 


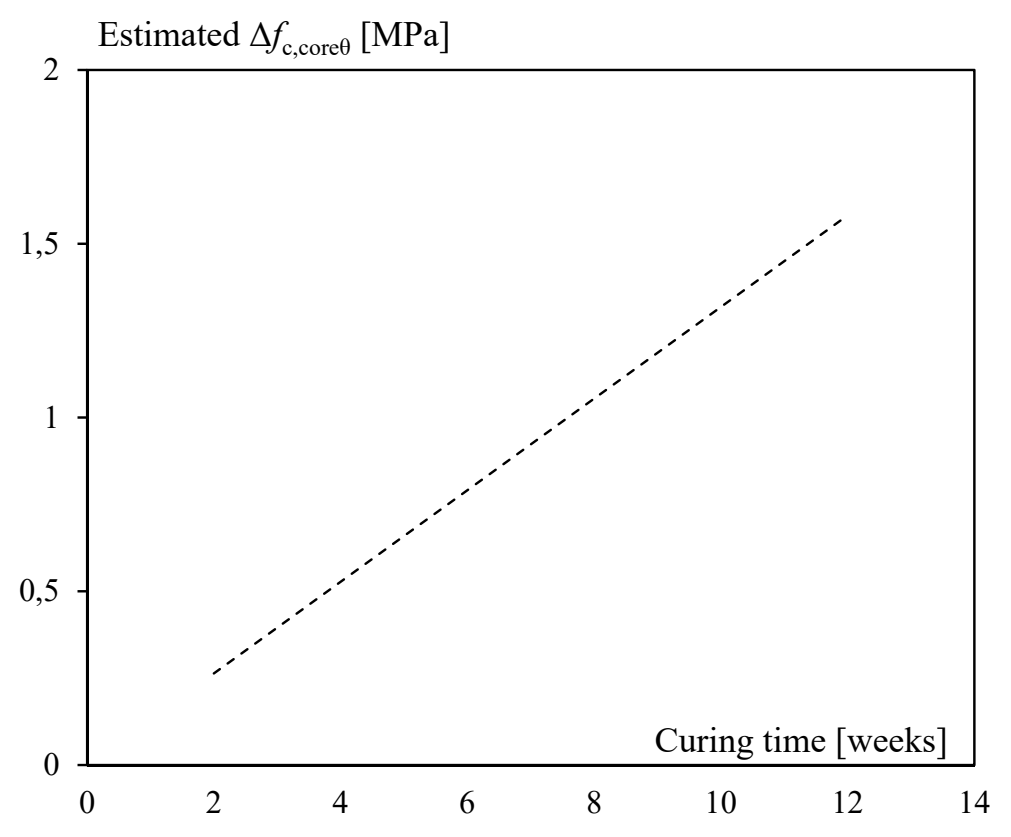

Figure 8: Estimated influence of the curing time on the anisotropy.

Table 8: Estimate of the regression coefficient

\begin{tabular}{lll}
\hline & Estimate & $p$-value \\
$\beta_{\text {dir }}$ & $-1.26 \mathrm{MPa}$ & 0.0033 \\
\hline
\end{tabular}

Based on the evaluation of the significance as well as the magnitude, it can be concluded that the influence of the curing time on the anisotropy is small.

The regression analysis identifies 1 possible outlier. However, a regression analysis where the possible outliers are excluded shows the same as the shown analysis. The $p$-value for $\theta_{\text {time }}$ increases to 0.65 . The outlier is excluded in the further analysis.

\subsubsection{Significance and magnitude of the anisotropy}

Since the first regression analysis shows that the influence of the curing time on the anisotropy is insignificant, the anisotropy is further studied by a regression model without the interaction effects. The following regression model is adopted:

$$
f_{\mathrm{c}, \mathrm{core}}=\beta_{0}+\beta_{\mathrm{dir}} x_{\mathrm{dir}}+\beta_{\text {time }} x_{\text {time }} \pm \varepsilon
$$

Interest goes to the regression coefficient $\beta_{\text {dir }}$, which provides an estimate on the anisotropy. The estimate and corresponding $p$-value of the regression coefficient are provided in Table 8.

The anisotropy is assessed through the $(i)$ significance and $(i i)$ the magnitude of the regression coefficient $\beta_{\text {dir }}$;

\section{i Significance}

The regression coefficient has a $p$-value lower than 5 percent. This means that there is strong evidence that the concrete core compressive strength is anisotropic.

ii Magnitude

The anisotropy is quantified by Equation (5) without the interaction effects:

$$
\Delta f_{\mathrm{c}, \mathrm{core}}=2 \beta_{\mathrm{dir}}
$$




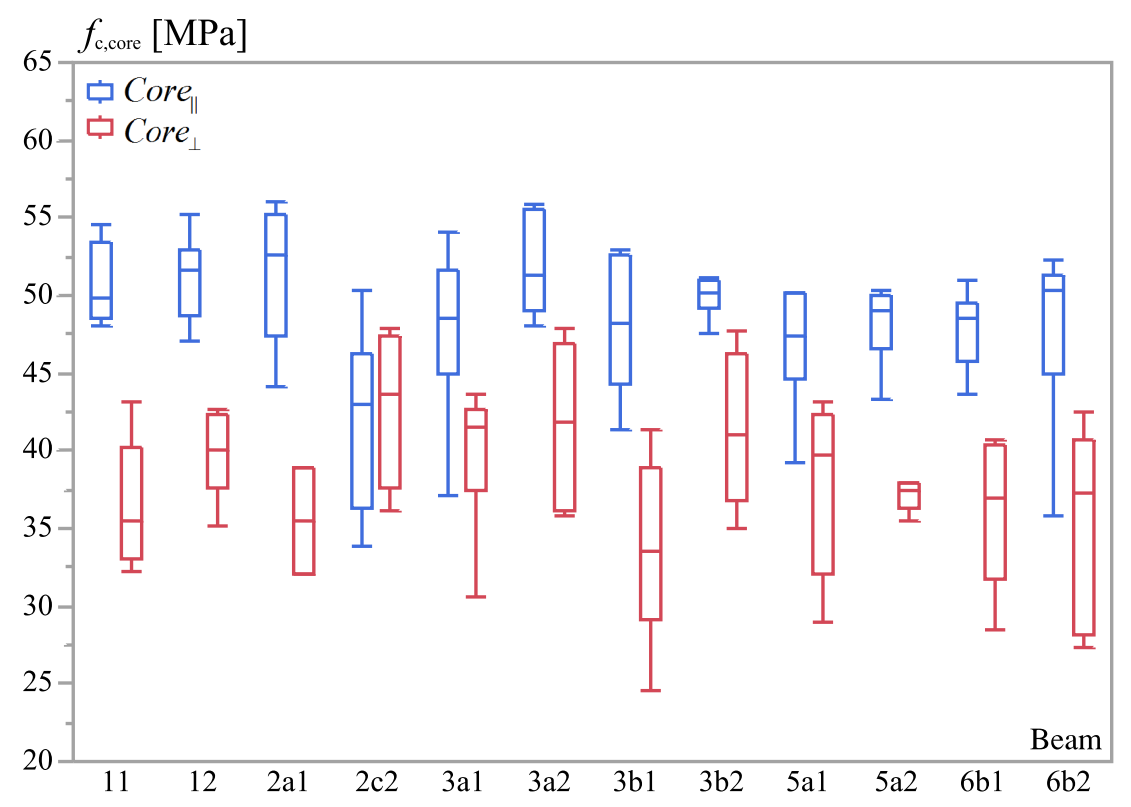

Figure 9: Box plot of the test results $\left(f_{\mathrm{c}, \mathrm{core}}\right)$ for Test series 3 .

The mean of the anisotropy of the concrete core compressive strength is $-2.5 \mathrm{MPa}$ and the corresponding 95 percent confidence interval is [-0.9 to $-4.1 \mathrm{MPa}]$. It is noted that the anisotropy is negative, contrary to Test series 1.

\subsection{Test series 3}

Figure 9 shows a box plot of the test results from Test series 3. From the box plot it can be observed that:

- $f_{\mathrm{c}, \mathrm{core} \perp}$ is in general lower than $f_{\mathrm{c}, \mathrm{core} \|}$.

- The anisotropy varies between the beams, most probably as a result of the extent of shear cracking in the beams due to previous loading.

Since no design parameters are studied in this test series the anisotropy can be studied by a Two Sample t-Test. The t-test shows that:

- The $p$-value is extremely low $(p<0.0001)$. This means that there is an extremely strong evidence that the concrete core compressive strength is anisotropic.

- The mean of anisotropy is $10.4 \mathrm{MPa}$ and the corresponding 95 percent confidence interval is [8.8 to $12.1 \mathrm{MPa}]$.

\section{Summary and discussion}

The experimental findings are summarised and discussed in this section. Sub-section 6.1 provides a schematic summary of the experimental findings. Sub-sections 6.2-6.6 provide discussions on the anisotropy and how it is affected by the studied design parameters and conditions. Finally, Sub-section 6.7 discusses a plausible physical explanation of the found anisotropy.

\subsection{Summary}

Table 9 shows a schematic summary of the experimental findings from Test series 1, 2 and 3. 
Table 9: Schematic summary of the experimental findings.

\begin{tabular}{|c|c|c|c|}
\hline & Investigation & Significance & Magnitude \\
\hline \multirow[t]{3}{*}{ Test series 1} & Anisotropy in slabs without load history. & $\begin{array}{l}\text { Extremely strong evidence that the concrete } \\
\text { strength is anisotropic. }\end{array}$ & The mean anisotropy is $4.5 \mathrm{MPa}$. \\
\hline & Influence of reference cylinder strength. & The influence is insignificant. & \\
\hline & Influence of the presence of reinforcement. & The influence is insignificant. & \\
\hline Test series 2 & Anisotropy in beams without load history. & $\begin{array}{l}\text { Strong evidence that the concrete strength is } \\
\text { anisotropic. }\end{array}$ & The mean anisotropy is $-2.5 \mathrm{MPa}$. \\
\hline & Influence of curing time. & The influence is insignificant. & \\
\hline Test series 3 & Anisotropy in beams with load history. & $\begin{array}{l}\text { Extremely strong evidence that the concrete } \\
\text { strength is anisotropic. }\end{array}$ & The mean anisotropy is $10.4 \mathrm{MPa}$. \\
\hline
\end{tabular}

\subsection{Reference cylinder strength}

The statistical analysis of the experimental results from Test series 1 shows that the reference cylinder strength, $f_{c, c y l i n}$, has no significant influence on the anisotropy in slabs without load history if the anisotropy is measured as a strength difference, $\Delta f_{\mathrm{c}, \mathrm{core}}$. In the literature, the anisotropy is often measured as a strength ratio, $f_{\mathrm{c}, \text { core } \|} / f_{\mathrm{c}, \mathrm{core} \perp}$. In that case, Test series 1 shows that the anisotropy is decreasing for increasing

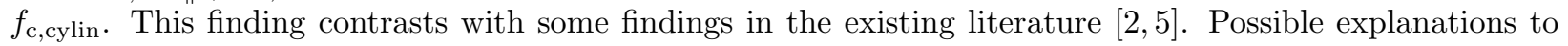
the diverging findings are provided below.

Johnston [2] concluded that for practical purposes $f_{c, \text { core } \|} / f_{c, \text { core } \perp}$ should be taken as a constant (approximately 1.08) independent of $f_{\mathrm{c}, \text { cylin }}$ (he tested concrete with $w / c$-ratios from 0.35 to 0.65 ). However, it should be noted that there was a variation in the mean value of $f_{\mathrm{c} \text {,core } \|} / f_{\mathrm{c}, \mathrm{core} \perp}$ for different $w / c$-ratios and the suggested constant of 1.08 was simply the average of these mean values.

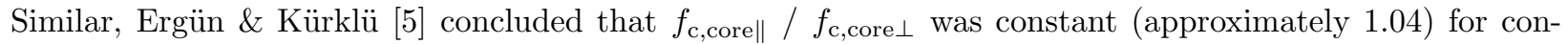
crete class $\mathrm{C} 16$ to $\mathrm{C} 22$ and $\varnothing 100 \times 200 \mathrm{~mm}$ cores. However, the conclusion was drawn by comparing the mean anisotropy without distinguishing between the concrete classes. Thus, like the case of Johnston, the significance of the influence of $f_{c, c y l i n}$ was not analysed.

Since Test series 1 shows that $f_{c, c y l i n}$ has no significant influence on $\Delta f_{c, \text { core }}$ and there exists no counterevidence based on statistical analysis in the literature, it is simpler to present the anisotropy as a strength difference, see equation (1), rather than the currently applied strength ratio. Adoption of the strength difference to describe the anisotropy would in fact shed new light on the apparently drastic finding of Hughes and Ash [1], who reported 50 percent anisotropy. By converting the results of Hughes and Ash into a strength difference, it is found that their results correspond to only $6 \mathrm{MPa}$ difference between $f_{\mathrm{c}, \text { core } \|}$ and $f_{\mathrm{c}, \mathrm{core} \perp}$. In this light, the finding in [1] seems less dramatic and is actually similar to the finding in this paper.

\subsection{Presence of reinforcement}

The statistical analysis of the experimental results from Test series 1 shows that the presence of reinforcement has no significant influence on the anisotropy in slabs without load history.

\subsection{Curing time}

The statistical analysis of the experimental results from Test series 2 shows that the curing time has no significant influence on the anisotropy in beams without load history. Since there is a direct relation between curing time and reference cylinder strength, the result here actually just confirms the conclusion above; namely that $f_{c, c y l i n}$ has no significant influence on the anisotropy (in terms of $\Delta f_{\text {c,core }}$ ). Hence, the curing time cannot be used to provide additional explanations to the large variation of the strength anisotropy (in terms of $\left.f_{\mathrm{c}, \text { core } \|} / f_{\mathrm{c}, \mathrm{core} \perp} \perp\right)$ published in the literature. The main explanation to the variation in the literature, based on the finding of Test series 1 , is most probably the influence of $f_{\mathrm{c}, \mathrm{cylin}}$. 


\subsection{Type of structural member}

To make the experiments representative for real structures, the anisotropy is investigated in both slab- and beam members (Test series 1 and Test series 2, respectively). To avoid the influence of load induced cracks, the members in both test series have no load history.

Test series 1 shows that the anisotropy is positive $(4.5 \mathrm{MPa})$ for slabs and Test series 2 shows that the anisotropy is negative $(-2.5 \mathrm{MPa})$ for beams. These results show that anisotropy is governed by more than just the weak interfaces or micro cracks between the cement paste and the undersurface of the large aggregate particles (which is the usual explanation). Otherwise, the anisotropy would have the same sign.

It is well known that $f_{\text {c,core }}$ has a spatial variation, see e.g. [4]. In the slabs of Test Series 1, the drilling locations for core $\perp_{\perp}$ and core $\|$ are sufficiently interspersed to neglect the influence on the measured anisotropy. For the beams of Test Series 2, on the other hand, the drilling locations for core $\perp_{\perp}$ and core $\|$ were at each end of the beams. Therefore, spatial variation might have influenced the measured anisotropy in Test Series 2. This may be the reason why the anisotropy varies for the four beams. However, it is unlikely that it has an influence on the overall tendency, namely the anisotropy was positive for the slab members and negative for the beams.

The reason for the influence of the type of structural member is further discussed in Sub-section 6.7.

\subsection{Anisotropy in members without and with load history}

Test series 1 and 2 show that the absolute strength anisotropy is less than $5 \mathrm{MPa}$ for structural members without load history; slabs as well as beams. The anisotropy is from a statistical point of view found to be significant. However, the magnitude is small from a structural point of view and would normally not need to be considered in structural analysis, provided the concrete has a sufficiently high reference cylinder strength, e.g. larger than say $30-35 \mathrm{MPa}$.

Test series 3 shows a strength anisotropy of approximately $10 \mathrm{MPa}$ for structural members with load history. This large anisotropy (as compared to that of Test series 1 and 2) is most probably a result of the extreme load history of the beams (they were tested to shear failure in all three shear zones prior to core drilling). Even though the cores were drilled from areas without visible cracks, micro damages and internal cracking were probably present in these areas due to the shear test. In this context, it is worth noting that existing structures in service often have a complex load history, but the magnitude of the loads is significantly smaller than the actual failure load of the structure. The anisotropy for existing structures in service may therefore be between the anisotropy found in Test series $3(\sim 10 \mathrm{MPa})$ and the anisotropy found in Test series 1 and 2 $(<5 \mathrm{MPa})$. As a consequence, it may not always be advisable to neglect strength anisotropy when assessing the residual load carrying capacity of existing structures, especially not when the structure clearly suffers from cracking, e.g. from alkali-silica reactions.

The reason for the influence of the load-history on the anisotropy is further discussed in Sub-section 6.7.

\subsection{Physical explanation of anisotropy}

The plausible explanation is based on a meso-level approach for both fresh and hardened concrete, where the concrete is considered to consist of aggregate particles and cement paste [14]. The explanation consists of two parts. The first part explains the formation of weak interfaces between the aggregate particles and the cement paste. The second part explains how these weak interfaces influence the compressive strength and induce strength anisotropy. Finally, the proposed explanation is qualitatively evaluated against the experimental tendencies observed in the presented tests as well as tests from the literature.

\section{Formation of weak interfaces}

The strength anisotropy originates from weak interfaces (or micro cracks) between the larger aggregate particles and the surrounding cement paste. There are many plausible reasons for formation of these weak interfaces, e.g. segregation in the fresh concrete, shrinkage [8], thermal effects, internal reactions (e.g. due to alkali silica reactions), external loads etc. [15]. A discussion of the weak interfaces is therefore needed to explain and understand the anisotropy found in this paper and in the literature. The main reason for the existence of weak interfaces in the considered test series is probably segregation and external loads. The proposed explanation is therefore based hereon. 


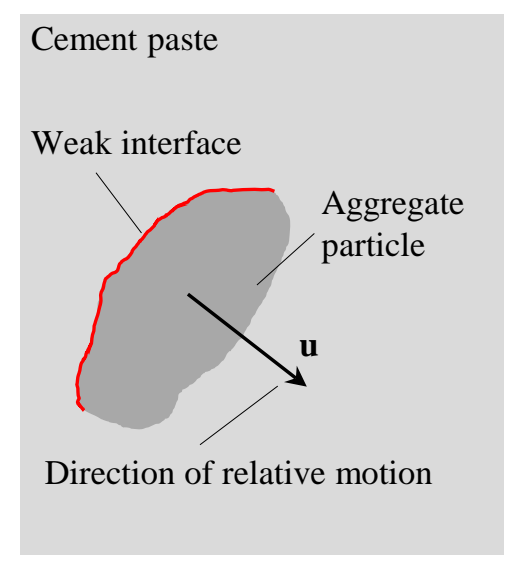

Figure 10: weak interface formed when an aggregate particle moves through the cement paste.

Segregation in the fresh concrete may lead to formation of weak interfaces when larger aggregate particles separate from the cement paste. The separation occurs when the aggregate particle moves through the, more or less, liquid cement paste. Figure 10 shows an aggregate particle moving (relatively) through the cement paste, where $\mathbf{u}$ describes the direction of the relative motion. Due to this relative movement, a weak interface forms between the cement paste and the surface of aggregate particle facing away from the direction of movement.

In some literature, segregation is described in terms of 'dynamic segregation' when the concrete is flowing, e.g. during casting or vibration, and 'static segregation' when the concrete is in rest, see e.g. [16].

For static segregation, it is well known that the aggregate particles move downward through the cement paste due to their higher density. Therefore, the static segregation leads to horizontal weak interfaces [17]. It is also well known that flowing concrete can lead to (dynamic) segregation as well. For example, if the concrete flows or is worked along the form or in case of improper use of vibrator [18]. However, dynamic segregation is often not mentioned in the discussion of strength anisotropy. The segregation in the flowing concrete occurs due to asynchronous movements of the cement paste and the aggregate particles during acceleration/deceleration of the concrete flow due to a density difference. The concrete flow and thereby the relative movements of the aggregate particles are strongly influenced by the geometry of the formwork. This is illustrated in Figure 11 and Figure 12, which schematically show the concrete flow for slabs and beams during casting and vibration, respectively.

Figure 11 shows the concrete flow trajectories and the formation of the weak interfaces during casting of a slab (left) and a beam (right). For the slab, the concrete flow trajectories will follow a radial/horizontal path when moving away from the pouring point. Due to a higher density (higher level of kinetic energy), the aggregate particles move horizontally through the cement paste during deceleration of the concrete flow. Therefore, weak interfaces will form vertically. For the beam, on the other hand, the concrete flow is confined by the boundaries of the narrow formwork. The flow therefore becomes more turbulent than in the case of the slab. Consequently, the relative movements of the aggregates and thereby the weak interfaces are randomly orientated.

Figure 12 illustrates the movements of the aggregate particles during internal vibration (needle vibrator) for a slab (left) and a beam (right), respectively. In the slab formwork, vibration induces mainly horizontal accelerations in the concrete. Due to the different densities, the aggregate particles will move horizontally through the cement paste and the weak interfaces will form vertically. In a beam formwork, vibration will also mainly induce horizontal accelerations. However, the form sides will confine the concrete flow and induce turbulence locally near these boundaries. Consequently, the weak interfaces are randomly orientated in the zone with turbulent concrete flow.

The segregation is a two-phasic phenomenon: first the dynamic segregation during casting and vibration and second the static segregation in the stagnant fresh concrete. In the following, dynamic segregation is considered to have the dominating effect on formation of the weak interfaces (and thereby on the anisotropy) and only in cases where dynamic segregation leads to randomly orientated weak interfaces (i.e. no anisotropy) 

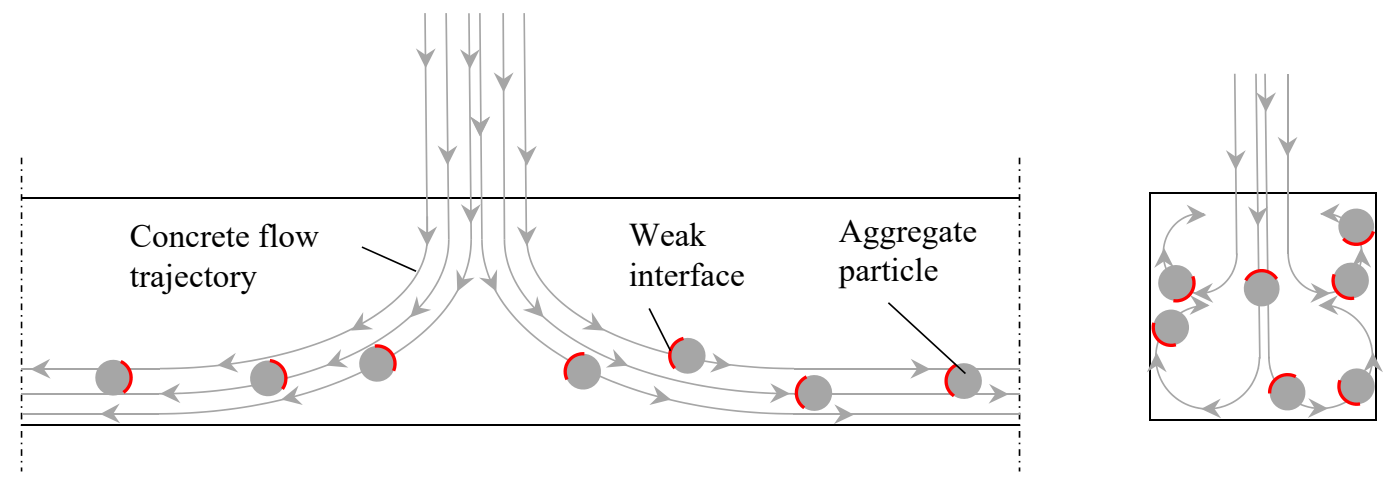

Figure 11: Concrete flow and weak interfaces during casting of slabs (left) and beams (right).
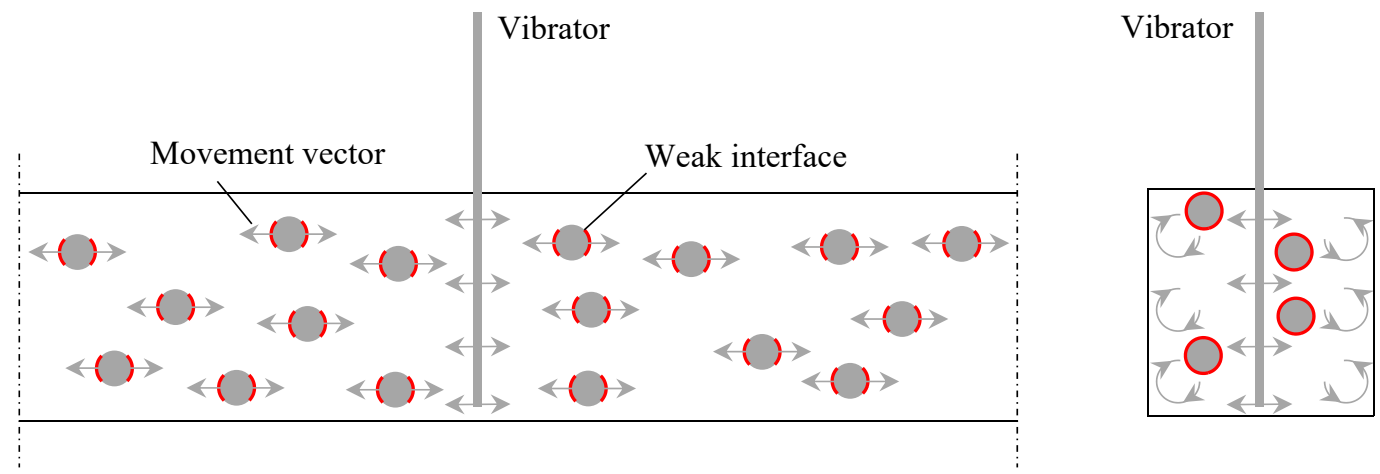

Figure 12: Movement of aggregate particles relative to the cement paste and weak interfaces during vibration of slabs (left) and beams (right).

the subsequent static segregation may have a governing effect. It follows from this assumption and from the discussions above that in narrow beams, static segregation will be governing and the horizontal weak interfaces will dominate. In slabs and wide beams, on the other hand, the dynamic segregation leads to vertical weak interfaces, which will dominate.

Another main reason for formation of weak interfaces is external loads. External loads induce crack planes formed perpendicular to the tensile stresses. The orientation of these crack planes can be very complex and depends on the load history and the static system of the structure. For example, it is expected that a pre-loaded two-way spanning slab has crack planes oriented in both span directions with various inclination. Consequently, vertically as well as horizontally drilled cores have crack planes (weak interfaces) orientated in all directions.

The orientation of the crack planes in slender/narrow beams is less complex. Since the out-of-plane stresses are neglectable, only crack planes perpendicular to the plan of the beam are expected, see Figure 13. This means that cores drilled horizontally ( core $_{\text {hori }}$ ) from pre-loaded beams only have crack planes (weak interfaces) parallel to the core's loading direction whereas the crack orientations in vertically drilled cores $\left(\right.$ core $\left._{\text {vert }}\right)$ are more random.

For slabs as well as beams, the crack orientation is highly depending on the drilling location in the structural member. This may also lead to significant spatial variation of the tested concrete strength.

The existence and orientation of the weak interfaces are not directly measurable [18] but are crucial for the compressive strength of drilled cores.

The influence of weak interfaces

There exist some explanations on how the weak interfaces induce a strength anisotropy, see e.g. [8]. The 


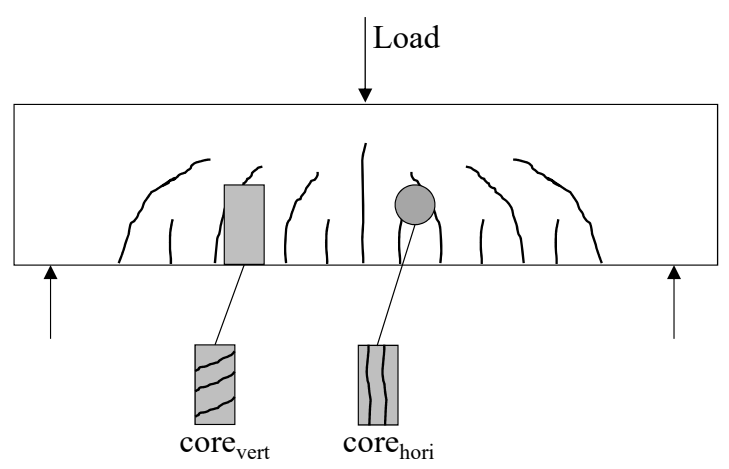

Figure 13: Orientation of load-induced weak interfaces (cracks) in vertically and horizontally drilled cores.

explanation in this paper is based on Vile's explanation of stress-carrying mechanisms around a single aggregate particle embedded in cement paste (continuous matrix), see Figure 14 (left) [19]. In Vile's explanation, initial microcracks are formed between the aggregate particle and the cement paste, parallel to the loading direction. These microcracks are stable until load-induced cracks are formed. It is assumed that the aggregate particle has a higher stiffness (or lower Poisson's ratio) than the cement paste. Therefore, shear stresses between the aggregate particle and the cement paste will be induced during loading. These shear stresses will confine a cement cone above and below the aggregate particle. The confinement increases the strength of these cement cones. First when shear ('en-echelon') cracks form between the confined cones and the surrounding cement paste, the development of the initial microcracks, and thereby the failure, can proceed. The favourable confinement depends naturally on the interface (bond) between the aggregate particle and the cement paste.

Weak interfaces can easily be included qualitatively in Vile's explanation. Figure 14 (centre) shows an embedded aggregate particle where the interface below the particle is weakened. The weak interface has a reduced ability to transfer confining shear stresses between the aggregate particle and the cement cone. Consequently, the compressive strength of the cement cone may be reduced to a degree where a compressive failure of cement cone occurs rather than a shear failure between the cement cone and the unconfined cement. In this case, the weak interface will reduce the compressive strength of the concrete.

Figure 14 (right) shows an embedded aggregate particle where the interface on the left side of the particle is weakened. Vile's explanation assumes that initial microcracks parallel to the loading direction are stable and the stresses in the aggregate particle are transferred by the confined cones until load-induced cracks form. Therefore, the weak interface does not affect the stress-carrying mechanisms and the compressive strength is thereby unaffected.

Overall, cores with weak interfaces perpendicular to the loading direction have a lower compressive strength than cores with weak interfaces parallel to the loading direction.

\section{Expected anisotropy}

According to the proposed explanation, the geometry of the structural member has a significant influence on the strength anisotropy for structural members without load history. In slabs and wide beams, it is

expected that $f_{\mathrm{c}, \mathrm{core} \|}$ is larger than $f_{\mathrm{c}, \mathrm{core} \perp}$ (positive anisotropy) due to the vertical weak interfaces from the dynamic segregation. In beams with a small width, it is expected that the horizontal weak interfaces due to static segregation will be dominating. Consequently, $f_{\mathrm{c}, \mathrm{core} \perp}$ is expected to be larger than $f_{\mathrm{c} \text {,corell }}$ (negative anisotropy). It was assumed that the 'static segregation' does only have a governing effect if the dynamic segregation does not lead to anisotropy. Thus, the anisotropy might be smaller when static segregation is governing (narrow beams) then when dynamic segregation is governing (slabs and wide beams).

Since the static segregation is assumed to have less influence on the anisotropy, it is expected that the strength difference is smaller than for slabs.

Since segregation is based on the movement of the aggregate particles relative to the cement paste in the fresh concrete, many factors may influence the orientation of the weak interfaces and thereby the anisotropy. For example the density, size and shape of the aggregate particles, viscosity of the cement paste and casting 

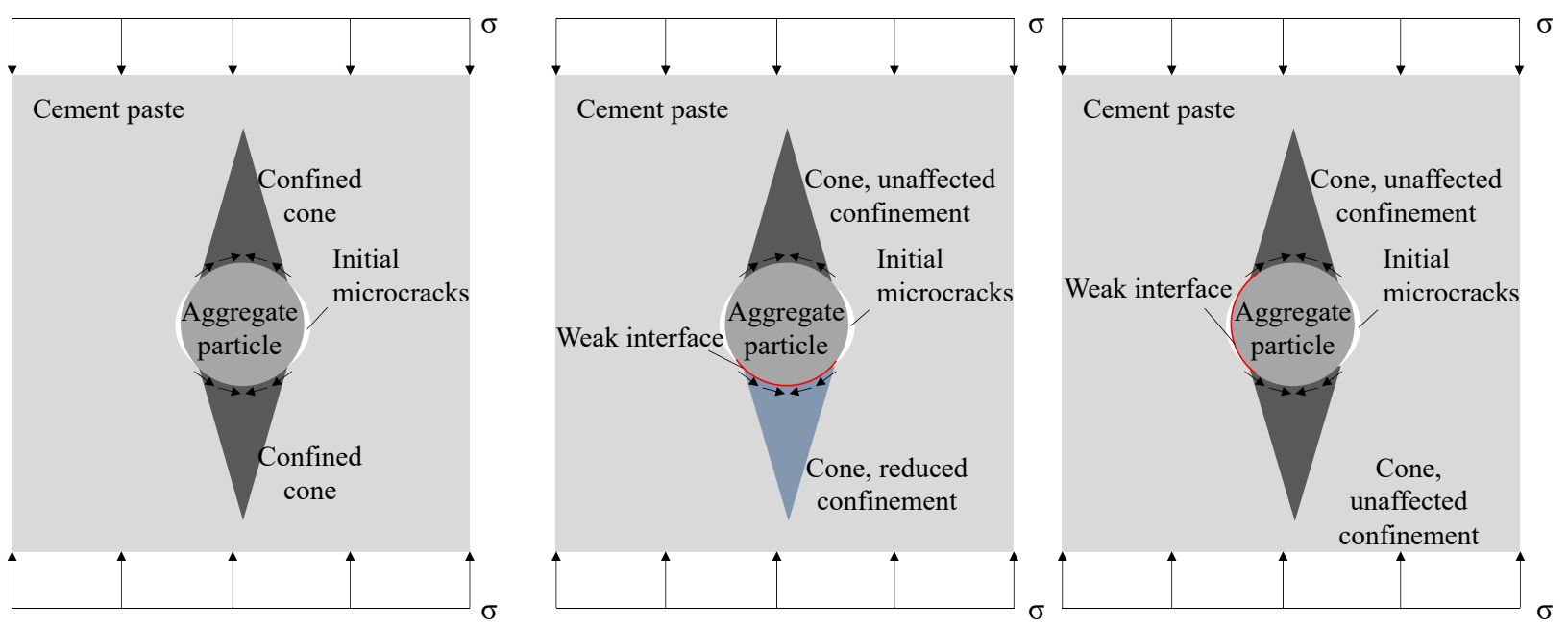

Figure 14: Stress-carrying mechanisms around a single aggregate particle embedded in cement paste. Left) The original explanation by Vile, adapted from [8]. Centre) The influence of a weak interface perpendicular to the loading direction. Right) The influence of a weak interface parallel to the loading direction.

and vibration procedures. Consequently, a large experimental scatter is therefore expected.

Also for structural members with load history, the geometry of the structural member has a significant influence. For slender beams, it is expected that $f_{\mathrm{c}, \text { core,hori }}$ is larger than $f_{\mathrm{c} \text {,core,vert }}$ due to the orientation of the crack planes. Due to the variation of cracks in the beam, it is expected that both $f_{\mathrm{c}, \text { core,hori }}$ and $f_{\mathrm{c} \text {,core,vert }}$ have a large scatter. For slabs, no difference between $f_{\mathrm{c} \text {,core,hori }}$ and $f_{\mathrm{c}, \text { core, vert }}$ is expected. However, due to the expected increased spatial variation, a large anisotropy may be found, especially for small sample sizes where it is not possible to sort out the influence of spatial variation.

\section{Relation between experimental tendencies and proposed explanation of anisotropy}

This paper has presented two test series on drilled cores from structural members without load history (Test series 1 and 2). The tendency of the test results agrees with the proposed explanation; i.e. the anisotropy for the slabs was positive (4.5 MPa) and negative and smaller for the beams (-2.5 MPa).

Den Uijl and Yang [6] found a positive anisotropy $(10.3 \mathrm{MPa})$ for beams with a width of $600 \mathrm{~mm}$. Due to the large width of the section it is expected that vertically orientated weak interfaces are formed due to dynamic segregation. Therefore, the test results are in line with the proposed explanation.

Van Mier [7] found no anisotropy in prisms with dimensions $700 \times 135 \times 135 \mathrm{~mm}$. Due to the small width of the cross section, turbulent concrete flows are expected during casting and vibration. This is in good agreement with the proposed explanation where a negative and small anisotropy is expected.

Ergün and Kürklü [5] found a slightly positive anisotropy $(0.6 \mathrm{MPa})$ for beams with a cross section of $200 \times 200 \mathrm{~mm}$. The fact that the anisotropy was reported to be small (i.e. neglectable) is in good agreement with the explanation due to the turbulent concrete flows during casting and vibration. The small positive anisotropy might be due to scatter or spatial variation, since core $\|$ and core ${ }_{\perp}$ were drilled from different beams.

Johnston found overall a positive anisotropy (-2 to $5 \mathrm{MPa}$ ) for cubes cut from rectangular specimens with dimensions of $750 \times 150 \times 150$ and $750 \times 100 \times 100 \mathrm{~mm}$. This is not in good agreement with the proposed explanation. However, Van Mier found no anisotropy for similar prisms cut from rectangular specimens. It should here be noted that Johnston showed a failure surface of a vertical prism after testing in uniaxial tensile, where horizontal weak interfaces are easily seen. The fact that the orientation of the weak interfaces is horizontal is in good agreement with the proposed explanation, where static segregation is expected to be governing.

This paper has also presented a test series on cores drilled from slender beams with load history (Test series 3 ). It was found that $f_{\mathrm{c}, \text { core,hori }}$ (corresponding to $f_{\mathrm{c}, \text { core } \|}$ ) was $10.3 \mathrm{MPa}$ larger than $f_{\mathrm{c}, \text { core,vert }}$ (corresponding 
to $\left.f_{\mathrm{c}, \text { core } \perp}\right)$. This is in very good agreement with the proposed explanation.

\section{Conclusions}

This paper presents a study on the anisotropy of the concrete core compressive strength by combining experimental investigation and statistical analysis. The main conclusions of the study are presented in this section.

- The reference cylinder strength does not have a significant influence on the absolute anisotropy $\left(\Delta f_{c, c o r e}\right)$ in members without load history.

- It has been argued that it is simpler to present the anisotropy as a strength difference rather than the currently applied strength ratio.

- The 50 percent anisotropy found by Hughes and Ash [1] should, if generalised, instead be interpreted as a strength difference of $6 \mathrm{MPa}$.

- The presence of reinforcement does not have a significant influence on the anisotropy in slabs without load history.

- The curing time does not have a significant influence on the absolute anisotropy in beams without load history.

- Positive anisotropy was found for slabs (Test series 1) while positive as well as negative anisotropy were found for beams (Test series 2 and 3 ).

- Weak interfaces due to dynamic and static segregation may explain the anisotropy in structural members without load history.

- The absolute anisotropy $\left(\left|\Delta f_{\mathrm{c}, \mathrm{core}}\right|\right)$ was found to be less than $5 \mathrm{MPa}$ for structural members without load history.

- The anisotropy for structural members that have been loaded to failure was found to be approximately $10 \mathrm{MPa}$.

- It has been argued that the anisotropy for existing structures in service may be between 5 and $10 \mathrm{MPa}$.

- Weak interfaces due to load-induced cracks may explain the anisotropy in structural members with load history.

\section{Acknowledgement}

\section{Test series 1 and 3}

The experimental programmes were carried out by the M.Sc. students Leif Aabjerg and Mikkel Visti Jørgensen.

The test slabs, beams and cylinders were produced and donated by Expan, a part of CRH plc.

\section{Test series 2}

The experimental programme was carried out by the B.Eng. students Anders Grue Johansen and Alexander Lind Henriksen.

The test beams and cylinders were produced and donated by Spæncom, a part of Consolis.

The authors would like to gratefully acknowledge the contributions. 


\section{References}

[1] B. Hughes and J. Ash, "Anisotropy and failure criteria for concrete," Materials and Structures, vol. 3, no. 6, pp. 371-374, 1970.

[2] C. Johnston, "Anisotropy of concrete and its practical implications," Highway Research Record, no. 423, 1973.

[3] A. M. Leshchinsky, "Anisotropy of concrete strength," Cement, Concrete and Aggregates, vol. 12, no. 2, pp. 117-119, 1990.

[4] F. M. Bartlett and J. G. MacGregor, "Cores from high-performance concrete beams," Materials Journal, vol. 91, no. 6, pp. 567-576, 1995.

[5] A. Ergün and G. Kürklü, "Assessing the relationship between the compressive strength of concrete cores and molded specimens," Gazi University Journal of Science, vol. 25, no. 3, pp. 737-750, 2012.

[6] J. Den Uijl and Y. Yang, "Comparative study of shear capacity on beams of 50-years old and new concrete-measuring report," tech. rep., Internal report Delft University of Technology, 2009.

[7] J. G. M. Van Mier, Strain-softening of concrete under multiaxial loading conditions. Technische Hogeschool Eindhoven, 1984.

[8] J. G. Van Mier, Fracture processes of concrete, vol. 12. CRC press, 1996.

[9] L. Aabjerg and M. V. Jørgensen, "Experimental study on correlation of concrete strength found from different methods," Master's thesis, University of Southern Denmark, 2016.

[10] K. L. Wind and J. G. Kjeld, "The influence of curtailed reinforcement on the strength of rc beam," BSc Thesis, University of Southern Denmark, 2016.

[11] P. Goos and D. Meintrup, Statistics with JMP: Hypothesis Tests, ANOVA and Regression. John Wiley \& Sons, 2016.

[12] B. L. Bowerman, R. T. O'Connell, E. Murphree, S. C. Huchendorf, and D. C. Porter, Business statistics in practice. McGraw-Hill/Irwin New York, 2003.

[13] S. G. Hansen, Statistical Analyses of Experimental Results. Internal note University of Southern Denmark, (The work is a part of a PhD project, it will be included in the dissertation of the author), 2017.

[14] F. Wittmann, "Structure of concrete with respect to crack formation," Fracture mechanics of concrete, vol. 43, no. 5, p. 6, 1983.

[15] M. P. Nielsen and L. C. Hoang, Limit analysis and concrete plasticity. CRC press, 2010.

[16] L. Shen, L. Struble, and D. Lange, "Modeling dynamic segregation of self-consolidating concrete," $A C I$ Materials Journal, vol. 106, no. 4, p. 375, 2009.

[17] K. Kovler and N. Roussel, "Properties of fresh and hardened concrete," Cement and Concrete Research, vol. 41, no. 7, pp. 775-792, 2011.

[18] A. M. Neville, Properties of concrete, vol. 5. Pearson Education Limited, 2011.

[19] G. Vile, "The strength of concrete under short-term static biaxial stress," in International Conference on the Structure of Concrete, 1968. 
Appendix

Appendix A 
Table A. 1: Measured compressive strengths for cores and cylinders in Test series 1 . The core heights are shown in brackets.

\begin{tabular}{|c|c|c|c|c|c|}
\hline \multicolumn{6}{|c|}{ Mix A } \\
\hline & \multicolumn{2}{|c|}{ Unreinforced } & \multicolumn{2}{|c|}{ Reinforced } & \multirow[b]{2}{*}{$f_{\mathrm{c}, \mathrm{cylin}}[\mathrm{MPa}]$} \\
\hline & $f_{\mathrm{c}, \text { core } \|}[\mathrm{MPa}]$ & $f_{\mathrm{c}, \mathrm{core} \perp}[\mathrm{MPa}]$ & $f_{\mathrm{c}, \text { core } \|}[\mathrm{MPa}]$ & $f_{\mathrm{c}, \text { core } \perp}[\mathrm{MPa}]$ & \\
\hline$\# 1$ & $33.5(195.4)$ & $29.4(195.5)$ & 39.9 (194.4) & $31.8(195.2)$ & 44.5 \\
\hline \#2 & $37.4(195.4)$ & $26.7(194.9)$ & $37.8(194.8)$ & $39.6(194.8)$ & 41.9 \\
\hline \#3 & $39.1(195.5)$ & $31.8(195.2)$ & $37.7(194.9)$ & $23.5(195.2)$ & 43.5 \\
\hline$\# 4$ & $39.0(195.3)$ & $29.0(194.8)$ & $36.0(195.2)$ & $32.2(195.0)$ & 44.1 \\
\hline$\# 5$ & $38.1(195.5)$ & $30.4(195.3)$ & $41.2(194.0)$ & $34.1(195.4)$ & 44.6 \\
\hline$\# 6$ & $34.5(195.2)$ & $28.7(194.5)$ & $41.5(194.4)$ & $41.6(194.6)$ & 42.5 \\
\hline$\# 7$ & $36.2(195.4)$ & $35.4(194.6)$ & $36.9(193.6)$ & $38.9(193.8)$ & \\
\hline \#8 & $35.9(193.2)$ & $33.6(195.4)$ & $37.2(194.8)$ & $33.1(195.1)$ & \\
\hline \#9 & $33.8(195.4)$ & $31.3(195.5)$ & $40.0(195.4)$ & $34.2(195.4)$ & \\
\hline \#10 & $35.6(195.7)$ & $27.2(195.3)$ & $38.7(195.2)$ & $36.5(195.2)$ & \\
\hline \#11 & $37.3(194.9)$ & $29.3(195.5)$ & $36.8(195.2)$ & $31.2(195.3)$ & \\
\hline$\# 12$ & $31.7(195.7)$ & $31.9(195.6)$ & $39.4(195.1)$ & $35.5(195.1)$ & \\
\hline \#13 & $33.2(195.6)$ & $30.5(193.4)$ & & $33.1(195.3)$ & \\
\hline$\# 14$ & $35.2(195.5)$ & & & $35.0(194.9)$ & \\
\hline \#15 & $31.1(195.7)$ & & & $30.6(194.3)$ & \\
\hline \#16 & $36.8(195.2)$ & & & & \\
\hline \#17 & $28.5(195.5)$ & & & & \\
\hline \#18 & 32.4 (195.6) & & & & \\
\hline \#19 & $33.3(195.7)$ & & & & \\
\hline
\end{tabular}

\begin{tabular}{llllll}
\hline \multicolumn{7}{c}{ Mix B } & \multicolumn{2}{c}{ Reinforced } & \\
\multicolumn{7}{c}{ Unreinforced } & $f_{c, \text { core } \|}[\mathrm{MPa}]$ & $f_{c, \text { core } \perp[\mathrm{MPa}]}$ & $f_{\mathrm{c}, \text { core } \|}[\mathrm{MPa}]$ & $f_{\mathrm{c}, \text { core } \perp}[\mathrm{MPa}]$ & $f_{\text {c,cylin }}[\mathrm{MPa}]$ \\
\hline$\# 1$ & $49.2(199.5)$ & $50.8(185.9)$ & $59.0(196.8)$ & $55.2(199.5)$ & 71.5 \\
$\# 2$ & $48.6(200.3)$ & $47.6(192.1)$ & $59.4(196.0)$ & $53.2(199.2)$ & 65.0 \\
$\# 3$ & $56.9(200.3)$ & $47.3(186.1)$ & $63.4(197.0)$ & $56.7(198.4)$ & 66.9 \\
$\# 4$ & $52.3(199.8)$ & $50.9(196.8)$ & $62.8(196.8)$ & $58.7(198.5)$ & 64.0 \\
$\# 5$ & $53.5(199.3)$ & $53.5(197.0)$ & $61.9(197.6)$ & $59.0(195.4)$ & 70.0 \\
$\# 6$ & $41.7(199.8)$ & $46.0(192.2)$ & $57.6(197.6)$ & $55.8(199.3)$ & 71.6 \\
$\# 7$ & $49.9(199.8)$ & $46.7(193.7)$ & $58.1(197.4)$ & $53.0(199.1)$ & \\
$\# 8$ & $54.6(199.3)$ & $44.7(198.3)$ & $60.3(196.7)$ & $53.6(195.3)$ & \\
$\# 9$ & $51.6(199.2)$ & $45.1(200.7)$ & $63.3(196.5)$ & $49.3(192.0)$ & \\
$\# 10$ & $56.6(198.3)$ & $54.1(198.4)$ & $62.9(197.7)$ & $48.9(195.1)$ & \\
$\# 11$ & $50.5(198.4)$ & $57.6(197.8)$ & $57.6(197.7)$ & $55.7(198.8)$ & \\
$\# 12$ & $52.9(198.5)$ & $42.5(197.9)$ & $59.7(197.0)$ & $54.6(197.5)$ & \\
$\# 13$ & $44.0(200.2)$ & & $60.7(197.5)$ & $50.8(197.5)$ & \\
$\# 14$ & $46.7(197.7)$ & & $58.8(197.0)$ & & \\
$\# 15$ & $52.9(196.0)$ & & & & \\
$\# 16$ & $52.0(196.0)$ & & & & \\
$\# 17$ & $48.0(199.0)$ & & & & \\
$\# 18$ & $48.3(199.5)$ & & & &
\end{tabular}


Table A. 2: Measured compressive strength for cores and cylinders in Test series 2.

\begin{tabular}{ccccccccccccc}
\hline & \multicolumn{3}{c}{$f_{\mathrm{c} \text { core } \|}[\mathrm{MPa}]$} & \multicolumn{4}{c}{$f_{\mathrm{c}, \text { core } \perp}[\mathrm{MPa}]$} & \multicolumn{4}{c}{$f_{\mathrm{c}, \text { cylin }}[\mathrm{MPa}]$} \\
& 2 & 4 & 8 & 12 & 2 & 4 & 8 & 12 & 2 & 4 & 8 & 12 \\
\hline$\# 1$ & 45.3 & 49.5 & 51.7 & 51.8 & 49.8 & 48.1 & 44.9 & 59.9 & 53.8 & 59.6 & 59.7 & 62.8 \\
$\# 2$ & $41.3^{*}$ & 49.9 & $49.9^{*}$ & 51.2 & 47.7 & 50.9 & 50.6 & 58.8 & 52.8 & 60.1 & 56.2 & 61.3 \\
$\# 3$ & $42.3^{*}$ & $42.4^{*}$ & $47.8^{*}$ & 56.2 & 46.2 & 48.2 & 55.7 & 55.2 & 51.0 & 57.1 & 61.3 & 56.4 \\
$\# 4$ & & 48.1 & $51.0^{*}$ & 53.3 & 46.2 & $49.8^{*}$ & 47.8 & 54.5 & 49.9 & 60.0 & & 62.1 \\
$\# 5$ & & & $52.1^{*}$ & 56.2 & & 49.8 & & 55.2 & & 58.4 & & 65.0 \\
$\# 6$ & & & & & & & & & & 58.8 & & \\
\hline
\end{tabular}

* Grinded in both ends

Table A. 3: Measured core compressive strength for Test series 3. The core height is shown in brackets.

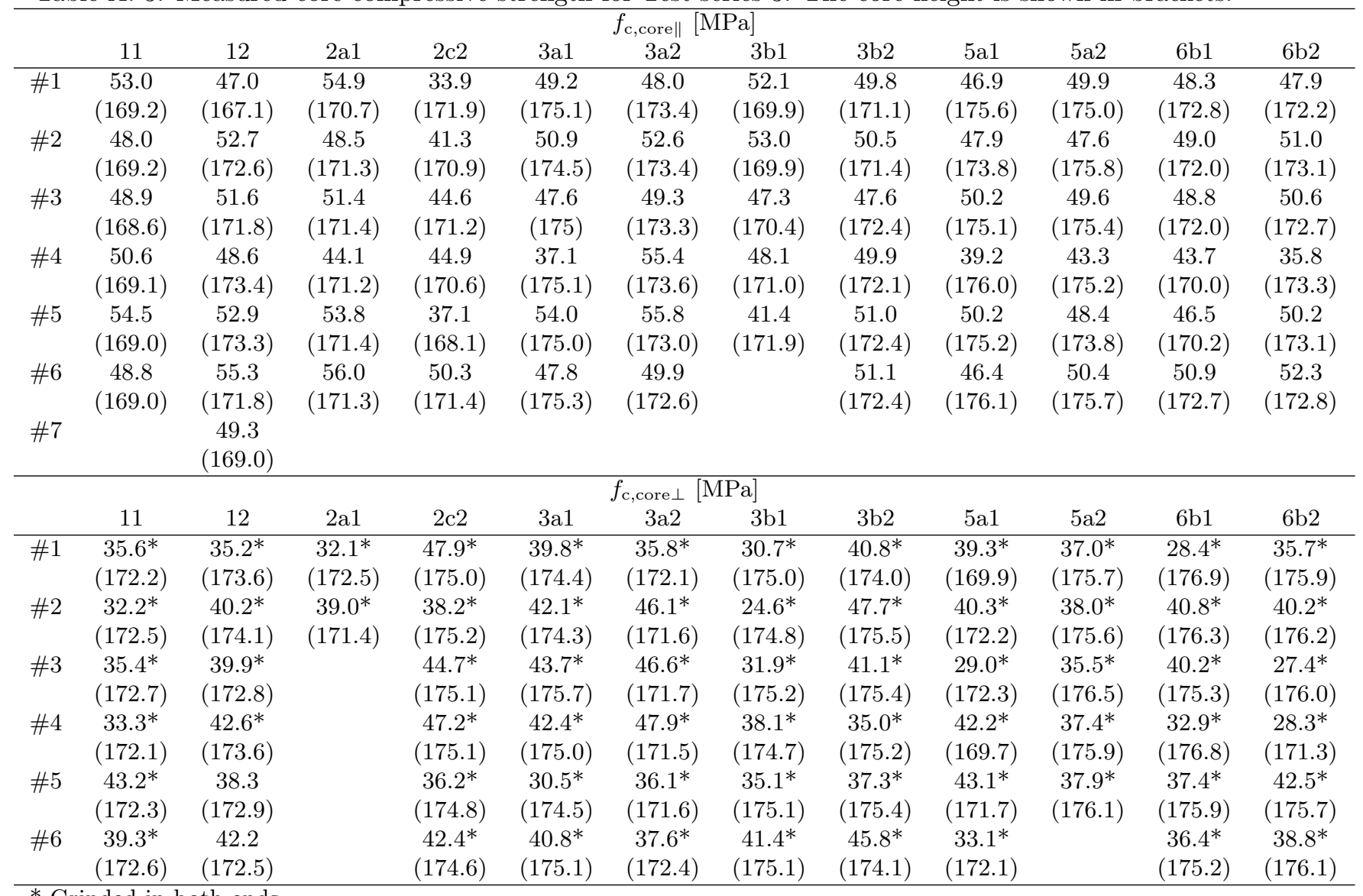

* Grinded in both ends 


\section{Appendix B}

The beams in Test series 3 had been used for testing the shear capacity for beams with curtailed reinforcement. Figure B.1 shows a beam and the reinforcement configuration. Details on the reinforcement and the beam heights are given in Table B.1. Further details are shown in [10].

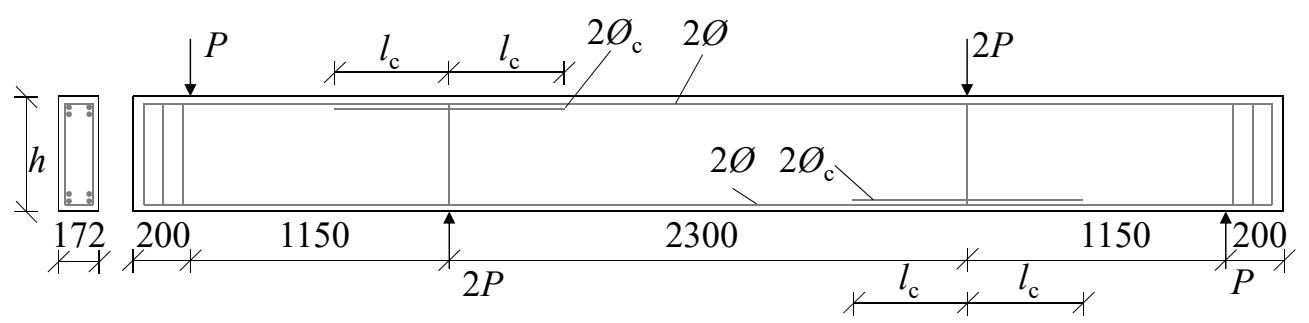

Figure B. 1: Schematisation of a beam used in Test series 3 .

Table B. 1: Details on the beams used in Test series 3: diameter of the general reinforcement $(\varnothing)$, diameter of the curtailed reinforcement $\left(\varnothing_{\mathrm{c}}\right)$, length of the reinforcement $\left(l_{\mathrm{c}}\right)$ and height of the beams $(h)$.

\begin{tabular}{lcccccccccccc}
\hline Beam & 11 & 12 & $2 \mathrm{a} 1$ & $2 \mathrm{c} 2$ & $3 \mathrm{a} 1$ & $3 \mathrm{a} 2$ & $3 \mathrm{~b} 1$ & $3 \mathrm{~b} 2$ & $5 \mathrm{a} 1$ & $5 \mathrm{a} 2$ & $6 \mathrm{~b} 1$ & $6 \mathrm{~b} 2$ \\
$\varnothing[\mathrm{mm}]$ & 16 & 16 & 16 & 16 & 12 & 12 & 20 & 20 & 16 & 16 & 16 & 16 \\
$\varnothing_{\mathrm{c}}[\mathrm{mm}]$ & 16 & 16 & - & - & 16 & 16 & 16 & 16 & 16 & 16 & 16 & 16 \\
$l_{\mathrm{c}}[\mathrm{mm}]$ & 500 & 500 & 500 & 500 & 500 & 500 & 500 & 500 & 750 & 750 & 500 & 500 \\
$h[\mathrm{~mm}]$ & 500 & 500 & 500 & 400 & 500 & 500 & 500 & 500 & 500 & 500 & 400 & 400 \\
\hline
\end{tabular}

